\title{
Practical Intelligence and the Limitations of Practitioners
}

\section{Multiple Forms of Knowledge, and Their Significance in Music and Musikvermittlung}

Tasos Zembylas

In this chapter I argue that knowledge in the broadest sense of the word is not only pivotal for any practice, but it is also the motor for innovation. Traditionally, academic scholars tend to overvalue the role of theory, as if theory could lead to practice. The concept of knowledge that I will present here goes far beyond academic epistemes. Knowledge in my understanding - in alignment with John Dewey (1916; Dewey/Bentley 1949), Gilbert Ryle (1949), Ludwig Wittgenstein ([1953] 1999) and Michael Polanyi $(1958,1966)$ - is constitutively interwoven with practices. Theoretical analyses of knowledge can be insightful, but they cannot shape or replace the practice as such. In order to become a good practitioner in Musikvermittlung, one does not have to read this research, yet reading it may support critical reflection on practice. Since the practice of Musikvermittlung consists of doings and sayings, the capacity for critical reflection is an inherent part of the professional practice.

As other contributors to this anthology highlight, there is a great variety of formats and situations ${ }^{1}$ where Musikvermittlung activities take place (see also Allwardt 2012: 3f.). In the following analysis, however, I refer primarily to formats of Musikvermittlung that have been established in concert halls and festivals of classical and contemporary art music ${ }^{2}$ which address adult audi-

Alternative formats have emerged in the last few decades, after an explicit critique of the traditional practice of Musikvermittlung, which was accused of mediating a narrow and normative concept of music and disseminating certain social biases against the musical cultures of lower social classes and marginalised groups ("sub-cultures"). music and implies a devaluation of other musical practices that are not included within 
ences. By focusing on this particular format, it is easier to relate the practice of Musikvermittlung to the main subject of my contribution, which is the role of multiple forms of knowledge in this practical field.

Formats of Musikvermittlung that contemporary audiences experience in many concert halls and festivals emerged from a particular historical tradition. In Europe, the performance of sacred music, and later of art music, was developed in such a way that it mainly cultivated spectatorship and listenership rather than active audience involvement, such as joining in by singing, clapping as rhythmic accompaniment, dancing, and spontaneous public responses to the music - although exceptions were permissible, for example in dance halls, or during particular ceremonies and celebrations in which the attendees were not always sitting in a contemplative modus. Furthermore, audiences generally experience art music produced by professionals, which is planned and managed by organisations such as concert halls, opera houses and festivals that sell tickets, thereby establishing an economic relationship between music, musicians and consumers.

Musikvermittlung professionals work with certain resources and in given settings; they are therefore affected by various formal and informal constraints according to the particular working conditions. Within this context, Musikvermittlung can best be understood as an attempt to promote cognitive access and enhance aesthetic experiences, often by providing audiences with cultural knowledge and facilitating musical listening. ${ }^{3}$ Yet in almost all its manifestations it does not have any 'revolutionary' aspirations to transform the dominant practice of listenership (i.e. sitting in a silent and contemplative modus) within the realm of classical and contemporary art music and its institutions. $^{4}$

this concept. Without ignoring the social and political critique of this conception, I have nevertheless used it because it is generally understood to refer to a certain musical genre. Yet the concept has a relatively open meaning, since its boundaries to other musical genres are in certain contexts permeable.

3 On a practical level, the goals of Musikvermittlung are diverse (Wimmer 2010: 91-93, 110) and reflect the heterogeneity of its addressees, and the various organisational directives and the demands of stakeholders.

4 There exists a rich critical discourse on the format, conventions and rituals of classical concerts - e.g. Martin Tröndle (2018). 


\section{Why Musikvermittlung?}

Classical formats of Musikvermittlung presuppose that music is not an artistic practice or a cultural good that audiences can take for granted. Music in its vast phenomenological variety of practices and formal developments includes very different musical languages - in the terminology of Ernst Cassirer ([1923] 1955) different "symbolic forms" - that appear in very diverse social and cultural situations. Accordingly, the basic justification of Musikvermittlung is that music needs mediation ${ }^{5}$ : firstly, because it is already mediated by different materials, systems of meaning, technologies, discourses and cultural practices; and secondly, because it demands certain basic competences for practicing certain activities, for example listening, singing, dancing, playing and creating music, coding and decoding, understanding, appreciating, talking about music and so on. From this point of view, the fundamental questions of Musikvermittlung revolve around its objectives, and the identification of methods and competences that enable people - those who are not involved in the creation and realisation of an artistic work ${ }^{6}$ - to gain rich and meaningful aesthetic experiences and occasionally new aesthetic insights. The adjective "new" assumes an indeterminate corpus of previous understandings, presuppositions and cultural beliefs that lead people to remain attached to certain images or ideas about music and particularly about art music (Wittgenstein [1953] 1999: § 109, 115, 309). Such images are, for example:

5 In Ceorg Wilhelm Friedrich Hegel's "Phenomenology of Spirit" ([1807] 2018) the concept of mediation refers to the transmission of Spirit in its different historical stages through manifold artistic forms. Any manifestation of the Spirit needs a medium and therefore mediation is a priori. Two hundred years later, one need not be a Hegelian to establish a relation between medium, form, meaning and understanding - see Niklas Luhmann ([1995] 2000), and for explicit reference to music see Wilfried Gruhn (2005).

6 Roland Barthes ([1967] 1977) proclaimed the "death of the author", which also seeks "to restore the place of the reader" (Barthes [1967] 1977: 143). This specific argument denies the relevance of authorial intentions and consequently ascribes to the audience an active role in constituting meaning. Since reading or listening to music is not a merely physiological but a profoundly cultural activity, I would like to underline that becoming a reader or a listener demands cultural education, i.e. extended knowledge and practical experience. People are usually familiar only with limited kinds of music and only after experiencing unfamiliar music practices do they become aware of what it takes to become a competent listener. 
- a somewhat static, work-centred perspective associated with certain dogmatic beliefs, e.g. faithfulness to the work of art, its original meaning, artistic essence or truth;

- a pre-social, and philosophically-speaking an idealistic idea, about the special status of art based on weighty metaphysical assumptions, e.g. the idea of genius, of autonomous, self-sufficient works of art, or of timeless masterpieces;

- a deep-seated conviction about the superiority of one's own culture, and more specifically about the European art music tradition.

If Musikvermittlung is to be enhancing and inspiring for us, its addressees, it should encourage us to change ourselves by expanding our cognitive and experimental capabilities and, as a result, intensify our aesthetic experience and reflection. This transformative process makes, according to Dewey ([1934] 1939: 35-57), the difference between a full experience and a mere impression. While a mere impression is rather superficial, a full experience is associated with learning which gives meaning to experience. Aisthesis, that is to say sensations and emotions, are central components of experience: "The esthetic", Dewey ([1934] 1939: 48) writes, "is no intruder in experience from without [...but rather] the clarified and intensified development of traits that belong to every normally complete experience." Thus Musikvermittlung that deals with aesthetic experience goes beyond learning about music. It addresses our understandings, tastes, identities, and emotional capabilities. Perhaps some practitioners in the field of Musikvermittlung believe that this assertion is exaggerated. Maybe - but I would nevertheless like to argue that placing such high expectations on Musikvermittlung can set a creative challenge to overcome established professional routines and invent new practical approaches for its audiences.

\section{Music and Musikvermittlung as Socially Organised Related Practices}

As mentioned above, aesthetic experiences are not unmediated and self-evident. The same holds true for artistic practices and artworks. These are always all mediated in multiple ways - materially, practically, immaterially, symbolically, culturally, socially, historically, etc. (Born 2005: 7f.; Cook 2013). Antoine Hennion elaborated this thesis as follows: "[T]aste, pleasure and meaning are contingent, conjunctural, and hence transient; and they result from specific 
yet varying combinations of particular intermediaries, considered not as the neutral channels through which predetermined social relations operate, but as productive entities that have effectivities of their own." (Hennion 2003: 84) This perspective can also be widened in an anthropological sense: individuals who are creating or experiencing an artwork (in the broadest sense of this term, including a wide range of cultural goods) are always embedded in particular situations, moods and forms of life (DeNora 2000: 40ff.; for a more general account of situatedness, see Schatzki et al. 2001). Therefore creating art, presenting art, perceiving art with all your senses, communicating art, reflecting, discussing with others and evaluating are activities built on knowledge and practical experiences - which is generally called enculturation. These requirements, however, are barely perceptible. Wittgenstein reflects on this when he asks:

“[H]ow can it be explained what 'expressive playing' is? Certainly not by anything that accompanies the playing. - What is needed for the explanation? One might say: a culture. - If someone is brought up in a particular culture and then reacts to music in such-and-such a way, you can teach him the use of the phrase 'expressive playing." (Wittgenstein 1970: §164, see also §157-172)

To understand what expressive playing means requires a kind of knowledge or, with reference to musicians, a practical artistic skill that entails collectively shared criteria (Wittgenstein, [1953] 1999: \$150, 182, 238, 269; Becker 1982: 40-67; Crispin/Östersjö 2017: 288-305). The knowing person must be embedded in and participate in a social world in order to appreciate different contexts of sense-giving and valuation, and to carry out practices himself or herself in a certain way (e.g. playing music expressively). Theoretical knowledge, as well as practical knowing in music - or to use Ryle's (1949: 27ff.) terminology, to "know that" and to "know how" - therefore presuppose a community of cultural practice that cultivates a certain musical tradition. All the various forms of knowledge are constitutively interwoven with practices, specifically with doings and sayings (Wittgenstein, [1953] 1999: \$6, \$19; Taylor 1995: 7). Yet the production and reproduction of a musical practice are largely discreet, because the where, how and when (i.e. the place, the medium and the time) through which we acquire knowledge and abilities can barely be fully identified. The history of practice is thus a tacit history, in the sense that practice has many aspects that lie beyond the reach of individual awareness, and also beyond what can be verbally articulated. Wittgenstein regards this practical background, constituting human agency and intelligibility, as 
a non-analysable whole. It was Pierre Bourdieu's great achievement to elaborate the concept of habitus ${ }^{7}$ in order to make the practical background of human agency accessible for sociological analysis.

In the same way as music, Musikvermittlung is a socially organised practice and most Musikvermittlung activities take place in specific organisational environments and are pre-structured by higher-chain cultural-managerial decisions (e.g. the music programme; the duration of a Musikvermittlung unit; the spatial and material conditions in which an event takes place; the number and selection of participants). What Musikvermittlung conveys (for example, the creative process of a musical work, the context of its creation, the aesthetic form and the formal relations of its elements, the art of presentation or performance practice of a work, as well as the sensual perception, reflection and evaluation of musical achievements) has - epistemologically speaking - a "tacit dimension", to borrow a term from Polanyi (1966). This "silent" dimension of musical knowledge often escapes our awareness, and it seems reasonable to assert that practitioners of Musikvermittlung "know more than [they] can tell" (Polanyi 1966: 4). In fact, communication about music "displays a knowledge that we cannot tell" (Polanyi 1966: 5). ${ }^{8}$

This brings me to the difference between "knowledge" and "knowing", and their dynamic relationships in music in general, as well as in Musikvermittlung in particular.

The critique of Bourdieu's concept of habitus for its deterministic traits is controversial, but not completely unwarranted. In early publications (e.g. Bourdieu [1972] 1977) Bourdieu introduces habitus as an explanatory concept to refer to regularities and the reproduction of social order. In later works he interprets this concept slightly differently:"The habitus goes hand in glove with vagueness and indeterminacy. As a generative spontaneity which asserts itself with an improvised confrontation with ever renewed situations, it obeys a practical inexact, fuzzy sort of logic, which defines one's normal relation to the world." (Bourdieu [1987] 1990: 77-78, cited after Bouveresse 1999: 62.)

8 Although Bourdieu does not refer to Polanyi, he arrives at a similar conclusion when he writes: "It is because subjects do not, strictly speaking, know what they are doing that what they do has more meaning than they know." (Bourdieu [1972] 1977: 79) 


\section{Knowledge and Knowing}

The term "knowledge" (or again in Ryle's words to "know that") is traditionally understood as a justified true belief, and that is why this meaning has been linked to the concept of scientific knowledge. In contrast, "knowing" (or in Ryle's terminology to "know how") signifies "something we do", as Dewey (1916: 331) puts it. It has no content that can be distinguished from action. Therefore knowing is always implicit in action (Ryle 1949: 57, Schön 1983: 56, for an overview see Neuweg 2004). However, both "knowledge" and "knowing" are theoretically complex, since they are closely associated and discussed with other concepts, e.g. the mind, experience, body, language, institutions, norms, power, ideology, paradigms, styles of thinking, communities of practice, etc. This means that using the terms "knowledge" and "knowing" - as here in the context of Musikvermittlung and musical practice - should incorporate these numerous facets.

In everyday life, knowledge is made manifest by being able to verbalise what one knows, make certain justified assertions, claim that an utterance is true (Wittgenstein, [1953] 1999: \$78). An assertion and a claim to truth can be criticised as true or false, as right or incorrect, and as warranted by facts or unwarranted. Knowing, however, can only be demonstrated when you perform something well, when you are better or more adept at dealing with certain tasks and problems than others. True and false are not appropriate evaluative categories for knowing; therefore other criteria of practical success or failure have to be used. It should be noted that theories of truth, as well as regimes of competence and further associated criteria of success, are volatile and socially contestable (Selinger/Crease 2006). What I want to emphasise here is that knowledge and knowing are fundamentally different. Accumulated knowledge leads to connoisseurship and scholarship. Accumulated knowing leads to mastery in the sense of "skilled action, [and] ability in execution" (Dewey [1934] 1939: 47). These considerations mark the distinction between an epistemology of propositional knowledge and the epistemics of practical knowing. In both cases the nature of claims, demonstrations, justifications and evaluations differ significantly.

Musikvermittlung as a cultural practice implicates both knowledge and knowing. Since Musikvermittlung presupposes connoisseurship - but not necessarily scholarship - it involves propositional knowledge (first and foremost broad historical and musicological knowledge), but also knowledge about the performing musicians. Musikvermittlung also requires practical knowing on 
several levels. At least some practical understanding of musical creation and musical performance are necessary to convey understanding and stimulate aesthetic experiences. Moreover, some practical insights are needed, such as to how to address, motivate, integrate, and stimulate different participating social groups in Musikvermittlung activities. Musikvermittlung can therefore be performed well or not, that is to say its practice can be improved up to a level of proficiency and mastery. Furthermore, since Musikvermittlung stimulates feelings and imagination, and supports interaction and dialogue with participants, it has an ethical dimension (Bowman 2016). Consequently, professional competence and mastery should not be understood merely in a 'technical' sense, but should also encompass the concept of practical wisdom (phronesis), i.e. a genuine interest in the well-being of people.

\section{Multiple forms of knowledge and knowing in musical professions}

As argued above, all kinds of musical practices, as well as the practices of Musikvermittlung, require knowledge and knowing (see also Rink et al. 2017; Cook 2018). I will now elaborate on this, exploring concrete examples and multiple forms of knowledge and knowing in various musical professions.

Musical practices are anchored in shared cultural traditions, collective experiences, habitualised ways of thinking and evaluative patterns. This does not mean, however, that this anchoring has a determining effect in the strictest sense. Indeed, the actions of a musician are formed in the respective specific situation (Joas 1996: 160f.). In the action process, there is a dynamic interplay between already acquired knowledge and a situational knowing in actu. I therefore use two different epistemic concepts that are both relevant to musical professions: forms of artistic practical knowing and forms of propositional knowledge. ${ }^{9}$

Both artistic practical forms of knowing and propositional forms of knowledge can be further differentiated. With reference to artistic practical forms of knowing there are three distinct forms: lished a few years ago - see Zembylas/Niederauer (2018); Zembylas (2014); Zembylas/Dürr (2009). 
- Knowing the working process

- Situative knowing

- Body knowing

\section{Knowing the working process}

Experienced artists usually heed those aspects that are conductive or detrimental to their own productivity. This practical knowing and awareness of the conditions and peculiarities of creative work processes is personal, meaning that in contrast to theoretical knowledge, it is not easily transferable but rather bound to the person who has had the relevant experiences (Polanyi 1958; see also the concept of intransitive understanding in Wittgenstein [1969] 1980, part III, $\$ 37$, 77ff. and Johannessen 1994: 240ff.). A further kind of knowing the working process, which is cumulatively generated on the basis of experience, is the technical-practical knowing of how to handle musical instruments and equipment, how to grasp their maximum performance spectrum, their "affordances" 10 and how to use them judiciously in specific cases to achieve certain results. This knowing is not merely theoretical and propositional even if some technical instructions exist. Trying out, experimenting and playing around are prototypical ways of generating technical-practical knowing. Hence, knowing the working process ultimately leads to familiarity with several working steps and tasks, and bestows a subjective certainty with regard to creative challenges. Familiarity and subjective certainty in the working process are not primarily conceived here as psychological concepts, but arise from the tacit dimension of all knowledge and knowing (Polanyi 1966: 195f.; Collins 2010: 6).

\section{Situative knowing}

Acts of perception that appear to be meaningful lead to situative experience in actu. The sensual feeling of the instrument while playing, as a result of tac-

10 James ]. Gibson (1979) introduced the term "affordance" to refer to the situational action-stimulating effect of objects. He thus pleaded for an activist interpretation of the relationship between people and objects. James G. Greeno (1994: 338) links "affordance" with "abilities" and points out that affordance is not something given, but rather arises interactively and is shaped by the abilities of those acting. Furthermore, when dealing with an object, not only is already existing knowledge used, but new knowledge can also emerge. 
tile, proprioceptive and kinesthetic perception, as well as the hearing of its sounds, are meaningful and action-guiding events (Leman/Maes 2014: 83f.). The meaning of perception is integrated into the action, which is why Donald Schön (1983) spoke of "knowing-in-action". However, the significance of sensual-situational perception does not negate the relevance of reflexive, discursive and intellectual components in composing or playing music. Perceptual judgements are only possible on the basis of a certain practical, cultural and epistemic background - think of the Wittgenstein quotation above. Musicians often say, with reference to their perceptual impression and perceptual judgement, e.g. when a sequence of music sounds sad, or humorous or wrong, that "you hear it" or "you feel it". Interestingly, they often refer to a generalised subject - "one hears it" - and avoid the first person "I". If we confront musicians with this observation, they refer to the immediacy of the judgement (Zembylas/Niederauer 2018: 91f.; Zembylas/Dürr 2009: 68, 97f., 108f.). Their perception and judgement formation are intuitive, sentient and not primarily analytic-reflexive. Allan Janik correctly argues that this immediacy results from practical experience: "Learning to see is thus learning to judge 'at a glance' that this complex before me is a significant unity, a Gestalt. This is a matter of judgement [...]. 'Seeing' in such situations is anything but a matter of perceiving discrete sense data, collecting them and then synthesising them." (Janik 1994: 41f.). According to Polanyi (1966: 44), it is essentially an act of tacit integration of discreet particulars leading to a focal whole.

\section{Body knowing}

The body is an organism able to generate knowing. It is a synaesthetic and an action-oriented entity. It creates basic ideas of space and time and provides existential certainty (see also the concept of somaesthetics, Shusterman 2000: 137ff.; Shusterman 2008). Furthermore, the human body - certainly also the bodies of many other animals - can be trained to cope with complex tasks. This multi-functionality is often understood as "embodied intelligence" (see Lakoff/Johnson 1999; Shapiro 2014). The attribute "intelligent" is justified, because the body, despite all the training and drilling, can do more than just reproduce what it has practised; under certain conditions the body can be creative. For this, artists have to adjust their body to a certain mood. These are subtle adjustments: the body tension achieved when one works standing; the body relaxation when lying down comfortably; stimulation through the 
enjoyment of chocolate, coffee or a glass of wine, etc. The body is prepared, so to speak, to act as a catalyst for ideas.

The corporeal response to perceptions and situations - such as goose bumps, palpitations or smiles - contains evaluations and judgements. In this sense, such resonances can be interpreted as physically-intelligible responses to the environment, i.e. to situations, objects and persons. Furthermore, the body generates knowing because it is constantly learning. Pianists, for example, speak of the knowledge of their fingers when they sit at the piano and their fingers tell them whether a sequence of notes feels good or whether a certain passage is playable (Sudnow 2001: 71f., 79). In no art form - not even in literary writing - is the body mute or absent. A bodiless aesthetic experience is a contradiction in terms.

With reference to propositional forms of knowledge, I also distinguish between three distinct forms:

- Scholarly knowledge

- Local knowledge

- Formal, technical knowledge.

\section{Scholarly knowledge}

The term scholarly knowledge refers to the theoretical, concept-based and scientific production of knowledge. The majority of musicians in the field of European art music have a profound knowledge of the historical and contemporary repertoire of their music culture; they are well-informed about music-related discourses, and deal with a wide range of texts from different fields such as music analysis, music theory, aesthetics, psychology of perception, etc. Their explicit knowledge is not only theoretical and formal, but often also practically relevant in several respects. For many musicians, non-musical works, including scholarly texts, are inspiring, i.e. they trigger thoughts and ideas, which flow into their creative work. Thus, scholarly knowledge, among others, provides a semantic framework through which, for example, structural relationships between individual tones acquire a certain meaning, or musical quotations and stylistic elements are associated with certain aesthetics. Nevertheless, scholarly knowledge is not genuinely practical because it is not an immediate condition for artistic agency (Duguid 2005: 114). 


\section{Local knowledge}

Under the category of local knowledge - also called context knowledge - I subsume knowledge of the local music business, music agencies, music publishers and funding organisations, the activities of other colleagues, of festivals and so on. Such knowledge also influences practical and creative action. Local knowledge is explicit, but differs from systematic scholarly knowledge because it primarily arises in everyday life rather than academic scholarly contexts. Practitioners do not judge its validity and relevance on the basis of the categories true/false, but mostly on the basis of their own involvement, interests and collectively established regimes of competence (Wenger [1998] 2002: 136f.). Local knowledge accompanies the everyday life of the artists, shapes their identity and consolidates their membership in a professional community of practice (Szivos 2014).

\section{Formal, technical knowledge}

Formal, technical knowledge refers to knowledge about the formal characteristics and functioning of instruments, devices, software etc. This knowledge is largely propositional, since there are relevant descriptions and instructions about it. Yet this formal knowledge alone does not ensure technical practical competence. Nevertheless, formal technical knowledge is important, for example, when composing, in order to be able to use the sound and technical potential of the instruments in a differentiated way, to consider the perspective of the performing musicians when writing, to integrate room acoustic elements or to communicate with other specialists, such as sound engineers.

\section{A Holistic Understanding of Knowledge and Knowing}

I am advocating a holistic understanding of the multiple forms of knowledge and knowing. All the various forms mentioned above should always be considered in their synergy and interdependence. Within some activities, certain forms of knowledge and knowing seem to dominate (see Polanyi's remarks on focal and subsidiary awareness, Polanyi 1958:57-59). Despite this dominance, however, other forms are not eliminated but are always co-present. We should therefore understand the various forms of knowledge and knowing not as op- 
posing but as complementary components that constitute artistic or aesthetic agency.

It seems important to emphasise the synergy of the various forms of knowledge and knowing. From an anthropological perspective, humans are, in addition to their practical anchoring in the world, deeply shaped by symbolic forms that human cultures have created and that are continuously used. Thus human understanding (e.g. of music) is their way of being in and making sense of their sensual experience (Johnson/Larson 2003: 78). It is indeed hardly possible to draw a sharp line between people's implicit access to their own aesthetic and meaningful experiences and their explicit understanding of them (e.g. of music) (Taylor 2006:32). Similarly, analytical cognitive processes cannot be clearly demarcated from synthetic cognitive processes, nor can general propositional knowledge be entirely distinct from inarticulate sensualpractical knowledge (Lakoff/Johnson 1999: 19f.). Therefore I would like to argue first, that the general propositional knowledge of artists is not only theoretical and abstract, but is intrinsically interwoven with other - sensual and motor - skills. Second, the change between a flow of action and a conscious distancing from material or work, i.e. between intuitive and reflexive working methods, is a typical characteristic of complex artistic activities.

\section{Extending the Theoretical: Some Consequences for the Practice of Musikvermittlung}

The analytical differentiation between knowledge and knowing has an impact on the discussion of Musikvermittlung. In conclusion, I want to propose three distinct considerations:

The first concerns a (de)mystification of acts of music-making and creation, especially in the context of classical art music. Many creativity psychologists emphasise the importance of talent and giftedness (e.g. Weisberg 2006: 769f.). Both concepts are legitimate, but they should not be understood as an innate disposition or personality trait that relativises the central importance of learning. Until now, talent and giftedness have been central but highly problematic categories used by professionals in music universities, concert halls and festivals to legitimise their selection process of students and young artists, and ultimately offer a widely accepted explanation for artistic success. Yet the simplistic and at the same time opaque meaning of both terms ignores the social and competitive character of artistic professions and natu- 
ralises artistic success. Thus both these terms - talent and giftedness - often have an ideological impact, since they promote a pre-social and inscrutable conception of artistic practice. Specifically, I suggest that in conversations and when working with musicians, practitioners in the field of Musikvermittlung should convey an understanding of artistic creative work by focusing on musicians' working conditions, everyday practices, collaborations and experiences.

The second consideration relates to non-propositional understanding. Non-propositional understanding is internally related to the limits of verbalisation, i.e. the limits of the ability to make sensual-sensing experiences as well as bodily sensations explicit. Since sensual-sensing experiences are not directly linguistically explicable, they can only be conveyed by resorting to analogies and metaphors. In order to understand this in concrete terms, I invite the reader to closely observe the linguistic and non-linguistic communication between a conductor and musicians during rehearsals. Our communicative counterpart can only understand the analogies and metaphors that we use (e.g. "a soaring melody", "the percussion should sound stormy, violent, dangerous", "the scream cut through the air"), if he or she understands the hint or nod that a linguistic picture contains (Lakoff/Johnson 1980: 115f.; Johnson/Larson 2003: 66-78). Since practitioners in Musikvermittlung "can know more than [they] can tell" (Polanyi 1966:4), they are constantly facing communicative challenges and limitations (Wittgenstein [1953] 1999: \$78). Consequently (as many practitioners do already), they elaborate further means of non-linguistic aesthetic communication and interaction appropriate to the different groups of Musikvermittlung addressees (see also Smilde et al. 2019: 119f.).

The third consideration concerns the deconstruction of claims of knowledge and competence. Deconstruction has two meanings here: it is used to analyse the construction principles of an entity; it is also critical and means the unmasking of unwarranted assertions. I have no doubt that practitioners in Musikvermittlung have a broad knowledge of music and many years of practical experience in their field; some of these professional experiences form habits and work routines. Intelligent routines are indispensable, but they must remain modifiable if a professional situation demands it. Otherwise, a situation can arise whereby practitioners become prisoners of their own realm of experience. The deconstruction of claims to knowledge and competence can therefore be twofold. One can take a closer look at the discourse features of one's own descriptions and comments on music. Do we sometimes 
use, for example, a transfiguring and celebratory discourse with music? And which criteria of quality or excellence are implicit in our statements? The point is to create spaces for a critical distance from dominant cultural theories and one's own musical preferences. And there is a self-reflective dimension here: do I tend to present my own judgements and preferences as universally valid? Do I tend to privilege European art music? And how do I deal with music from other musical (sub)cultures that I am not familiar with? Nevertheless, the questioning of beliefs and certainties is not an end in itself, but rather makes productive scepticism effective. A willingness to criticise and negotiate social and cultural meanings and valuations is a central component of any lively search for new aesthetic insights and experiences.

In the title of this chapter I refer to the intelligence and limitations of practitioners, implying that practitioners in Musikvermittlung acquire continuously new learning experiences in the course of their professional life, which can lead to a new orientation of their practice. By re-examining their understanding and methods, their professional skills expand. This process implies, as Schön put it, reflection-in-action and reflection-on-action (Schön 1983: 26-29; also Polanyi 1966: 19). The first is largely implicit, the second explicit, and both represent the two ends of a continuum of reflective practice. Since the agency of practitioners is shaped not only by their knowledge and capabilities, but also by professional constraints, their practice is structured by internal and external limitations - e.g. what they do not know or are not able to perform, and what managerial decisions, institutional structures and limited resources impact on their actions. Both their practical intelligence, as well as their practical limitations, are constitutive for the development of their practice.

This anthology addresses the innovative potential of Musikvermittlung. If we take situatedness and contextuality in the practice of Musikvermittlung seriously, then we can address two aspects of innovative potentials. The first concerns the contents and methods of Musikvermittlung as regards the variety of addressees, the modes of reflective dialogue and participation, and the ways of creating shared experiences and of negotiating meanings. ${ }^{11}$ The sec-

11 Constanze Wimmer (2010: 100-115) discusses the quality of contents, as well as of applied methods, in the offerings of Musikvermittlung. Her approach is practice-oriented and surely fruitful for practitioners and cultural organizations. My remarks in this chapter are indirectly related to her discussion of quality, though they are set on a more general and philosophical level. 
ond relates to the organisation of Musikvermittlung. As a rule, the majority of Musikvermittlung activities in the field of classical and contemporary art music are one-off events (usually lasting around one hour) with participants that professionals meet only once. Due to this lack of continuity, it is virtually impossible to think about a systematic development of aesthetic capabilities. Yet unless there is continuity when engaging in arts, and unless there is an expansion of one's own capabilities, it is extremely unlikely that aesthetic experiences can trigger a transformative process. In order to conceive and stimulate the innovative potential of Musikvermittlung, we should also question the current corseting of its implementation, so as to negotiate new and better conditions for it to develop and flourish.

\section{Bibliography}

Allwardt, Ingrid (2012): Musikvermittlung, [online]: http://www.miz.org/st atic_de/themenportale/einfuehrungstexte_pdf/archiv/allwardt_2012.pdf [17.06.2019].

Becker, Howard S. (1982): Art Worlds, Berkeley: University of California Press. Barthes, Roland ([1967] 1977): The Death of the Author, in ibid.: Image-MusicText, London: Fontana Press, 142-148.

Born, Georgina (2005): On Musical Mediation: Ontology, Technology and Creativity, in: Twentieth-Century Music, Vol. 2, 7-36.

Bourdieu, Pierre ([1972] 1977): Outline of a Theory of Practice, Cambridge: Cambridge University Press.

Bourdieu, Pierre ([1987] 1990): In Other Words: Essays Towards a Reflective Sociology, Cambridge: Polity Press.

Bouveresse, Jacques (1999): Rules, Dispositions and Habitus, in: Schusterman, Richard (ed.), Bourdieu: A Critical Reader, Oxford: Blackwell, 45-63.

Bowman, Wayne D. (2016): Artistry, Ethics and Citizenship, in: Elliot, David J./Silverman, Marissa/Bowman, Wayne D. (eds.), Artistic Citizenship: Artistry, Social Responsibility, and Ethical Praxis, New York: Oxford University Press, 59-80.

Cassirer, Ernst ([1923] 1955): The Philosophy of Symbolic Forms. Vol. I: Language, New Haven: Yale University Press.

Collins, Harry (2010): Tacit and Explicit Knowledge, Chicago: University of Chicago Press. 
Cook, Nicholas (2013): Beyond the Score: Music as Performance, Oxford: Oxford University Press.

Cook, Nicholas (2018): Music as Creative Practice. Studies in Musical Performance as Creative Practice, New York: Oxford University Press.

Crispin, Darla/Östersjö, Stefan (2017): Musical Expression from Conception to Reception, in: Rink, John/Gaunt, Helena/Williamon, Aaron (eds.), $\mathrm{Mu}$ sicians in the Making: Pathways to Creative Performance, Oxford: Oxford University Press, 288-305.

DeNora, Tia (2000): Music in Everyday Life, Cambridge: Cambridge University Press.

Dewey, John (1916): An Added Note as to the 'Practical', in: ibid. Essays in Experimental Logic, Chicago: University of Chicago Press, 330-334.

Dewey, John ([1934] 1939): Art as Experience, New York, Capricorn Books.

Dewey, John/Bentley, Arthur (1949): Knowing and the Known, Boston: The Beacon Press.

Duguid, Paul (2005): "The Art of Knowing”: Social and Tacit Dimensions of Knowledge and the Limits of the Community of Practice, in: Information Society, 21, 109-118.

Gibson, James J. (1979): The Ecological Approach to Visual Perception, Boston: Houghton Mifflin.

Greeno, James G. (1994): Gibson's Affordances, in: Psychological Review, 101(2), 336-342.

Gruhn, Wilfried (2005): Understanding Musical Understanding, in Elliott, David J. (eds.), Praxial Music Education: Reflections and Dialogues, Oxford: Oxford University Press, 98-111.

Hegel, Georg Wilhelm Friedrich ([1807] 2018: Phenomenology of Spirit, Cambridge: Cambridge University Press.

Hennion, Antoine (2003): Music and Mediation: Towards a New Sociology of Music, in: Trevor, Herbert/Clayton, Martin/Middleton, Richard (eds.), The Cultural Study of Music, London: Routledge, 80-91.

Janik, Allan (1994): The Concept of Knowledge in Practical Philosophy, Innsbruck: Brenner Archiv, unpublished manuscript.

Joas, Hans (1996): The Creativity of Action, Chicago: University of Chicago Press. Johannessen, Kjell (1994): Philosophy, Art and Intransitive Understanding, in: Johannessen, Kjell/Larsen, Rolf/ Åmås, Knut O. (eds.), Wittgenstein and Norway, Oslo: Solum Forlag, 217-250.

Johnson, Mark/Larson, Steve (2003): "Something in the Way She Moves" Metaphors of Musical Motion, in: Metaphor and Symbol, 18(2), 63-84. 
Lako, George/Johnson, Mark (1980): Metaphors We Live By, Chicago: University of Chicago Press.

Lako, George/Johnson, Mark (1999): Philosophy in the Flesh: The Embodied Mind and Its Challenge to Western Thought, New York: Basic Books.

Leman, Marc/Maes, Pieter-Jan (2014): Music Perception and Embodied Music Cognition, in: Shapiro, Lawrence (ed.), The Routledge Handbook of Embodied Cognition, London: Routledge, 81-89.

Luhmann, Niklas ([1995] 2000): Art as a Social System, Stanford: Stanford University Press.

Neuweg, Hans Georg (2004): Tacit Knowing and Implicit Learning, in: Fischer, Martin/Boreham, Nicholas/Nyhan, Barry (eds.): European Perspectives on Learning at Work: The Acquisition of Work Process Knowledge. Luxembourg: Office for Official Publications for the European Communities, 130-147.

Polanyi, Michael (1958): Personal Knowledge: Towards a Post-Critical Philosophy. London: Routledge.

Polanyi, Michael (1966): The Tacit Dimension, London, Routledge.

Rink, John/Gaunt, Helena/Williamon, Aaron (eds.) (2017): Musicians in the Making. Pathways to Creative Performance, Oxford: Oxford University Press.

Ryle, Gilbert (1949): The Concept of Mind, London: Hutchinson.

Schatzki, Theodore/Knorr Cetina, Karin/Savigny, Eike von (eds.) (2001): The Practice Turn in Contemporary Theory, London: Routledge.

Schön, Donald (1983): The Reflective Practitioner. How Professionals Think in Action. Aldershot: Ashgate.

Selinger, Evan/Crease, Robert (eds.) (2006): The Philosophy of Expertise, New York: Columbia University Press.

Shapiro, Lawrence (ed.) (2014): The Routledge Handbook of Embodied Cognition, London: Routledge.

Shusterman, Richard (2000): Performing Live: Aesthetic Alternatives for the Ends of Art, Ithaca: Cornell University Press.

Shusterman, Richard (2008): Body Consciousness: A Philosophy of Mindfulness and Somaesthetics, Cambridge: Cambridge University Press.

Smilde, Rineke/Heineman, Erik/de Wit, Krista/Dons, Karolien/Alheit, Peter (2019): If Music be the Food of Love, Play on: Meaningful Music in Healthcare, Utrecht: Eburon.

Sudnow, David (2001): Ways of the Hand. A Rewritten Account, Cambridge: MIT Press. 
Szivós, Mihály (2014): A Practice-Oriented Classification of Tacit Knowledge for the Research into Creativity and Innovation, in: Polanyiana, 1-2 (23), 21-30.

Taylor, Charles (1995): Overcoming Epistemology, in: ibid. (ed.), Philosophical Arguments, Cambridge (MA): Harvard University Press, 1-19.

Taylor, Charles (2006): Merleau-Ponty and the Epistemological Picture, in: Carman, Taylor/ Hansen, Mark B. N. (eds.), The Cambridge Companion to Merleau-Ponty, Cambridge: Cambridge University Press, 26-49.

Tröndle, Martin (ed.) (2018): Das Konzert ${ }^{I I}$. Beiträge zum Forschungsfeld der Concert Studies, Bielefeld: transcript.

Weisberg, Robert W. (2006): Modes of Expertise in Creative Thinking: Evidence from Case Studies, in Ericsson, Anders K./Charness, Neil/Feltovich, Paul J./Hoffman, Robert R. (eds.), The Cambridge Handbook of Expertise and Expert Performance, Cambridge: Cambridge University Press, 761-787.

Wenger, Etienne ([1998] 2002): Communities of Practice: Learning, Meaning, and Identity, Cambridge: Cambridge University Press.

Wimmer, Costanze (2010): Exchange-Die Kunst, Musik zu vermitteln. Qualitäten in der Musikvermittlung und Konzertpädagogik, Salzburg, Stiftung Mozarteum, https://www.kulturmanagement.net/Themen/Exchange-Die-Kun st-Musik-zu-vermitteln,837 [19.7.2020].

Wittgenstein, Ludwig (1970): Zettel, Berkeley: University of California Press.

Wittgenstein, Ludwig ([1969] 1980): Philosophical Grammar, Oxford: Blackwell.

Wittgenstein, Ludwig ([1953] 1999): Philosophical Investigations, Oxford: Blackwell.

Zembylas, Tasos/Dürr, Claudia (2009): Wissen, Können und literarisches Schreiben. Eine Epistemologie der künstlerischen Praxis, Wien: Passagen Verlag.

Zembylas, Tasos (2014): Forms of Knowing in the Literary Writing Process, in: ibid (ed.), Artistic Practices. Social Interactions and Cultural Dynamics, London: Routledge, 112-131.

Zembylas, Tasos/Niederauer, Martin (2018): Composing Processes and Artistic Agency: Tacit Knowledge in Composing, London: Routledge. 


\section{Biographical note}

Tasos Zembylas has a PhD in Philosophy from the University of Vienna. He has been the Professor for Cultural Institutions Studies at the mdw - University of Music and Performing Arts Vienna since 2003. In 2009 he was Visiting Professor at the Zeppelin University in Friedrichshafen, Germany. His research specialisations include the sociology of artistic practices, the institutional analysis of art worlds, and public cultural funding policies. 